Geopolítica(s) Revista de estudios sobre espacio y poder ISSN: 2172-3958

\title{
La política exterior China y su proyección hacia América Latina y el Caribe en el siglo XXI. Imaginarios y representaciones geopolíticas
}

\author{
Gisela Brito ${ }^{1}$
}

Recibido: 29 de marzo de 2017 / Aceptado: 24 de marzo de 2018

Resumen. Las relaciones entre la República Popular China y los países de América Latina y el Caribe han experimentado un incremento sustancial en las últimas dos décadas, fundamentalmente en el ámbito de los intercambios económicos, pero también en el de las relaciones políticas. El propósito de este trabajo es analizar la política exterior de China hacia la región latinoamericana y caribeña desde la perspectiva de la geopolítica crítica. Para ello, en primer lugar, se examinan los imaginarios y representaciones espaciales que configuraron la particular "forma de ver el mundo" del gigante asiático, especialmente los principios de desarrollo pacífico y cooperación de beneficio mutuo, y cómo éstos se proyectan en sus relaciones con otros actores en el escenario internacional. En segundo lugar, se analizan los códigos geopolíticos que orientan la actual política exterior de China hacia América Latina y el Caribe. El texto argumenta que la estrategia subyacente consiste en construir hegemonía inscribiendo a los países de la región en su particular forma de concebir el escenario global, en el marco del interés del gigante asiático por ocupar posiciones de mayor relevancia en el diseño de las reglas de juego del sistema internacional.

Palabras clave: China; política exterior; América Latina y el Caribe; geopolítica crítica; imaginación geopolítica.

\section{[en] China's Twenty-First Century Foreign Policy in Latin America and the Caribbean. Imaginaries and Geopolitical Representations}

\begin{abstract}
Over the last two decades, relations between China and the Latin American and the Caribbean countries have seen an exponential growth, especially as concerns economic exchange, but also from a political perspective. Drawing on Critical Geopolitics, the article discusses China's foreign policy towards the Latin American and Caribbean region. It first explores the imaginaries and spatial representations that shape China's particular way of "seeing the world". It pays special attention to the principles of peaceful development and mutual benefit cooperation, and the way in which these inform China's relations with other actors in the international scenario. The article then analyses the geopolitical codes orienting China's current foreign policy in Latin America and the Caribbean. It is argued that China's implicit strategy is to construct hegemony by locating the region's countries within her particular vision of the global scenario, thus consonant with China's pursuance of an enhanced position to intervene in the design of the international system.
\end{abstract}

$1 \quad$ Universidad Complutense de Madrid.

E-mail: giselabr@ucm.es 
Keywords: China; foreign policy; Latin America and the Caribbean; critical geopolitics; geopolitical imagination.

\section{[pt] A política exterior Chinesa e sua projeção para América Latina e o Caribe no século XXI. Imaginários e representações geopolíticas}

Resumo. As relações entre a República Popular Chinesa e os países de América Latina e o Caraíbas
têm experimentado um incremento substancial nas últimas duas décadas, fundamentalmente no âmbito
dos intercâmbios económicos, mas também no das relações políticas. O propósito deste trabalho é ana-
lisar a política exterior Chinesa para a região latino-americana e caribenha desde a perspetiva da geo-
política crítica. Para isso, em primeiro lugar, se examinam os imaginários e representações espaciais
que configuraram a particular "forma de ver o mundo" do gigante asiático, especialmente os princípios
de desenvolvimento pacífico e cooperação de benefício mútuo, e como estes se projetam em suas rela-
ções com outros atores no cenário internacional. Em segundo lugar, analisam-se os códigos geopolíticos
que orientam a atual política exterior de Chinesa para América Latina e o Caribe. O texto argumenta
que a estratégia subjacente consiste em construir hegemonia inscrevendo aos países da região em sua
particular forma de conceber o palco global, no marco do interesse do gigante asiático por ocupar po-
sições de maior relevância no desenho das regras de jogo do sistema internacional. Palavras-chave: Chinesa; política exterior; América Latina e o Caribe; geopolítica crítica; imaginação geopolítica.

Sumario. Introducción. 1. La geopolítica como una práctica discursiva. 2. La política exterior de China. 2.1. El posicionamiento de China en el mundo del siglo XXI: la doctrina del "desarrollo pacífico". 3. América Latina y el Caribe en la imaginación geopolítica de China. Conclusiones. Bibliografía.

Cómo citar: Brito, Gisela (2018) "La política exterior China y su proyección hacia América Latina y el Caribe en el siglo XXI. Imaginarios y representaciones geopolíticas". Geopolítica(s). Revista de estudios sobre espacio y poder, vol. 9, núm. 1, 63-85.

\section{Introducción}

Desde inicios del siglo XXI, las relaciones entre la República Popular China (en adelante, China) y los países de América Latina y el Caribe (ALC) han experimentado un incremento sustancial, fundamentalmente en el ámbito de los intercambios económicos, pero también en el de las relaciones políticas. El propósito de este trabajo es analizar la política exterior de China hacia América Latina desde la perspectiva de la geopolítica crítica tal como la entiende Agnew, es decir como aquella que se ocupa de "indicar las representaciones que están en la base de la política exterior de determinados Estados" (2005a: 8). Para ello se analizarán las representaciones espaciales ligadas a la "imaginación geopolítica moderna" (Agnew, 2005a: 2) presentes en los códigos geopolíticos que orientan las políticas de China en sus relaciones con América Latina y el Caribe. En otras palabras, nos interrogamos acerca de las representaciones espaciales que configuran su particular "forma de ver el mundo" y cómo éstas se proyectan en sus relaciones con otros actores, en particular con los países de América Latina y el Caribe.

Retomando a Ó Tuathail y Dalby, Cairo (2005) distingue tres ámbitos de la geopolítica: 
1. El de la construcción de modelos geopolíticos (geopolítica formal)

2. El de los códigos geopolíticos que orientan la política exterior de los Estados (geopolítica práctica)

3. El de la construcción de representaciones sobre el espacio global a partir de las prácticas populares (geopolítica popular).

Este trabajo se sitúa en el ámbito de la geopolítica práctica. Entendiendo los códigos geopolíticos como el "conjunto de supuestos estratégicos que elabora un Gobierno sobre otros Estados para orientar su política exterior" (Taylor, 1994: 85), se analizan un conjunto de documentos oficiales sobre política exterior y discursos pronunciados por líderes políticos en los cuales cristalizan elementos clave en la configuración de la imaginación geopolítica china en el siglo XXI. Si bien este trabajo pretende abordar los discursos geopolíticos de la política exterior de China hacia América Latina, en primer lugar, se realiza una revisión de los principales ejes que configuran la política exterior China en las últimas décadas, sobre todo en el periodo abierto a partir de la finalización de la Guerra Fría. Aunque el conjunto de materiales analizados no es exhaustivo, el criterio selectivo ha sido la relevancia de los mismos en función del objetivo específico de este trabajo: identificar los supuestos espaciales que subyacen a la política exterior de China hacia América Latina y el Caribe. Los textos analizados son: el Libro Blanco: Ascenso Pacifico de China (2011), el documento Posición china para la Cooperación Sur-Sur (2003), el Informe entregado en 2012 por el ex Presidente Xu Jintao al XVIII Congreso del Partido Comunista Chino $(\mathrm{PCCH})$ y el Informe presentado por el Presidente Xi Jinping ante el XIX Congreso del PCCH en 2017. En el ámbito específico de ALC: el Documento sobre la política de China hacia América Latina y el Caribe emitido en 2008 y su versión actualizada (2016), la Declaración de Beijing (2015), el Plan de Cooperación CELAC-China 2015-2019 (2015), el discurso pronunciado por el Presidente Xi Jinping en la apertura del I Foro CELAC-China, celebrado en enero de 2015, el cual constituyó un hito en las relaciones entre ambos actores y la Declaración de Santiago (2018), producto del II Foro CELAC-China.

\section{La geopolítica como una práctica discursiva}

En este trabajo adoptamos el enfoque de la geopolítica crítica, la cual "se ocupa de estudiar (y deconstruir) la forma de ver el mundo que va a definir el escenario de la política internacional" (Cairo, 2005: XV), por lo cual se dejan de lado las perspectivas de la geopolítica tradicional basadas principalmente en el análisis de las estructuras espaciales como fundamento de la prácticas y relaciones interestatales. A diferencia de estas últimas, la perspectiva crítica otorga un rol central a la relación dialéctica entre, por un lado, la construcción de representaciones espaciales y, por otro, las prácticas espaciales (Cairo, 2005: xiii). De ahí que desde este punto de vista se defina la geopolítica como una "práctica discursiva" (Ó Tuathail y Agnew, 1992, cit. en Cairo, 2005: xii) a partir de la cual se elaboran y difunden ciertas representaciones del espacio que orientan - a la vez que son influidas por- las prácticas de los actores en el espacio de la vida material.

Desde la perspectiva de la geopolítica crítica es posible rastrear un conjunto de principios que configuran y orientan las prácticas de la política mundial en la 
modernidad. Estos principios configuran lo que Agnew denomina "imaginación geopolítica moderna", entendida como un conjunto de presupuestos que se naturalizan dando lugar a cierta forma de "ver el mundo" que atraviesa las relaciones internacionales desde el siglo XVI (2005a: 7).

El surgimiento y desarrollo del sistema capitalista y la forma de organización estatal surgida en la etapa posterior al Tratado de Westfalia (1648) dieron lugar a la emergencia de nuevos presupuestos en torno a la forma de percibir el espacio terrestre. En este sentido, la imaginación geopolítica moderna puede pensarse como un constructo de ideas que "incluye a la par que orienta la teoría y la práctica de la política mundial" (Agnew, 2005a: 1). Y como tal no es inmutable, sino que está relacionada con procesos históricos contingentes que no suponen ni una continuidad lineal ni rupturas abruptas. De ahí que, tal como señala Agnew, los elementos de continuidad en la imaginación geopolítica moderna se pueden agrupar en torno a cuatro principios básicos:

- La concepción imaginada del mundo como un todo, que solo tuvo lugar en modernidad, y que es asimismo uno de sus componentes constitutivos. Esta idea a la vez contiene dos elementos surgidos en la expansión europea y el "encuentro" con territorios hasta el momento desconocidos: 1) la separación entre el observador y el "mundo" entendido como preexistente, y 2) la presunción de que los lugares desconocidos podían representar zonas de peligro o amenaza, a partir de lo cual se configura una "jerarquía de lugares, de lo conocido a lo desconocido, de lo más seguro a lo más peligroso" (Agnew, 2005a: 17-18). Las "geografías binarias" basadas en la construcción de un "otro" a partir del cual definir un "yo", el caso de Occidente-Oriente entre otros, organizan el mundo en pares contrapuestos en las cuales se "vinculaban ideas sobre el tipo de las prácticas económicas y políticas con las concepciones geopolíticas del funcionamiento del mundo" (Agnew, 2005a: 37).

- La conversión del tiempo en espacio proyectada desde un centro (Europa) que se erige como un parámetro idealizado a partir del cual los demás territorios se clasifican en función del grado de "atraso" o "desarrollo" alcanzado en una escala progresiva cuyo punto de llegada es el modelo de Occidente. Como señala Agnew, "esta manera de pensar solo fue posible porque se creía que el tiempo tenía la misma extensión que el mundo, es decir, adquirió la forma de aquí (Occidente), que es ahora, y del allí (el Resto), que era antes. Con ello se naturaliza la idea ficticia de que todos los «otros» pueden potencialmente salir de su «atraso» $\mathrm{y}$ «desarrollarse» alcanzando el status de «moderno»" (2005a: 53-54).

- Una percepción espacial del poder, asociado de manera exclusiva a Estados entendidos como unidades territoriales. Este principio de la imaginación geopolítica moderna está vinculado a la "trampa territorial" de asumir que el poder está repartido entre Estados que serían los únicos actores en la política mundial (Agnew, 2005a). Dicha trampa territorial se organiza a partir de tres supuestos geográficos: 1) los Estados son soberanos dentro de su territorio, 2) todo lo externo conlleva una lógica diferente de los procesos que se dan al interior de las fronteras nacionales, y 3) el Estado territorial, al ser garante del orden interno, contiene geográficamente a la sociedad. 
- Consecuencia de lo anterior, el cuarto principio que está en el origen de la imaginación geopolítica moderna es la presunción de que el espacio internacional es escenario de una disputa inevitable entre Estados que luchan por imponerse unos sobre otros. La tensión lógica entre el presupuesto de que todos los Estados son iguales en función de la idea de soberanía y las desigualdades en el reparto de poder en la escala internacional encuentra resolución en la instauración de la idea de que todos los Estados tienen iguales condiciones de partida y que las jerarquías en el espacio internacional son producto de sus éxitos o fracasos en la competición con otros Estados. Este espacio de lucha por la supremacía se configura como un espacio anárquico de competencia en donde son nulas las posibilidades de cooperación entre unos y otros, pues solo estaría regido por impulsos de "acción egoísta espontánea" (Agnew, 2005a: 85).

La configuración de la imaginación geopolítica moderna está estrechamente vinculada a la expansión de Europa hacia el resto del mundo. Es "eurocéntrica" en su origen, pero posteriormente se expande espacial y temporalmente hacia otras regiones y hacia el futuro permeando las representaciones acerca de la política mundial y las relaciones entre Estados en el espacio internacional.

Si bien la imaginación geopolítica moderna no ha permanecido inmutable a lo largo del tiempo, existen continuidades de los principios mencionados que se reactualizan en diferentes contextos históricos, lo que evidencia su vigencia incluso en la actualidad. Resultado de la interacción entre los principios que dan sustento a la imaginación geopolítica moderna y las condiciones materiales en diferentes contextos históricos se configuraron lo que Agnew denomina "eras geopolíticas". Desde el siglo XIX hasta la finalización de la Guerra Fría se sucedieron tres eras ${ }^{2}$ caracterizadas por el hecho de que ciertas prácticas se erigieron en hegemónicas a partir de la instauración de consensos que pasaron a orientar las dinámicas interestatales. La geopolítica civilizatoria de principios del siglo XIX, que "se basaba más en el antagonismo entre el espacio europeo y los demás" fue sucedida por la geopolítica naturalizadora de finales del siglo XIX y principios del XX, la cual se centró principalmente en "las demandas territoriales e imperiales de Estados rivales cuyos intereses eran económicos y cuyas identidades eran raciales". Posteriormente a la Segunda Guerra Mundial y hasta la finalización de la Guerra Fría se desarrolló la era de la geopolítica ideológica basada "en la competición entre los modelos de modernidad representados por URSS y los EE UU" (Agnew, 2005a: 135).

La culminación de la Guerra Fría supuso el inicio de un periodo marcado por la incertidumbre acerca de la organización de la política mundial. No existe acuerdo sobre cómo será la reconfiguración de los fundamentos de la geopolítica global (Agnew, 2005a).

2 La noción de "era" que utiliza Agnew corresponde a la intención de enfatizar que se trata de una periodización en cierto sentido más flexible que la que deriva de la noción de ciclos de hegemonía basada en "órdenes geopolíticos" en los que el Estado hegemónico ordena el sistema interestatal, ya sea las que enfatizan el componente militar o geoestratégico (Modelski, 1987; Brzezinski, 1998) o diferentes perspectivas que ponen énfasis en la aspectos económicos (Wallerstein, 2004; Taylor, 1994), pues no contempla cortes taxativos sino más bien entrelazamientos de elementos de la imaginación política moderna que dan lugar a consensos de ideas que se tornan hegemónicos conformando un nuevo sentido común compartido. 
El principal elemento de continuidad proveniente de la era de la geopolítica ideológica son los procesos iniciados en los años 1970 que dieron forma a una economía cada vez más globalizada estimulada por la hegemonía de EE UU, y una arquitectura institucional internacional creada con el objetivo de proyectar su visión político-económica a escala global (Agnew 2005a; Agnew, 2005b). Los procesos de globalización económica y desterritorialización continúan profundizándose desafiando la lógica de la primacía estatal: "La consecuencia geopolítica más importante del desplazamiento de las fronteras estatales por los flujos de personas, bienes y capital que se mueven entre nudos locales dentro de redes globales, ha sido el deterioro de los procesos y explicaciones convencionales de la jerarquía espacial" (Agnew, 2005a: 99).

El periodo de la hegemonía estadounidense tuvo como consecuencia la creación de una economía globalizada que desborda la territorialidad de los Estados. En el periodo de la Pos-Guerra Fría, el derrumbe de la URSS posiciona a EE UU como "la única Gran Potencia con un mensaje global: consumo de masas, libertad personal, propiedad privada, mercados y democracia electoral" (Agnew 2005a: 96). Desde la perspectiva de Agnew, en el periodo de la Pos-Guerra Fría el "régimen de acceso a los mercados" (2005a: 138) estimulado por EE UU se erige como el modelo hegemónico en el sentido de que constituye un conjunto de ideas extendido a escala global que incluye y orienta las prácticas de diversos actores de la política mundial. La desterritorialización de la producción, la emergencia de una economía de flujos transnacionales, el surgimiento de instancias de gobierno o acuerdos económicos de carácter supraestatal estimula reconfiguraciones espaciales que se superponen con - y desafían - la lógica de los Estados territoriales complejizando el espacio global. Todo ello supone un momento de crisis de los presupuestos que guiaban la imaginación geopolítica moderna (Agnew, 2005a). La espacialidad global organizada en torno a Estados territoriales soberanos se ve fuertemente cuestionada evidenciándose su carácter contingente. Y la lucha por la supremacía tal como era entendida en etapas precedentes se reconfigura al menos en dos sentidos. En primer lugar, cobra cada vez mayor relevancia la idea de que el crecimiento económico de los países se vincula a su integración en la economía mundial. Con ello se evidencia un grado mayor de interdependencia a partir del cual se privilegia la resolución de disputas en el marco de instancias políticas y no militares. En segundo lugar, la situación de interdependencia creciente y el hecho de que la cantidad de grandes potencias sea muy pequeña conlleva grandes "incentivos para la cooperación entre ellas" (Agnew, 2005a: 96).

Muchos de estos elementos de la imaginación geopolítica moderna permean los códigos geopolíticos que orientan la política exterior China al menos desde la segunda mitad del siglo XX hasta el presente. A continuación nos interrogamos acerca de cuáles son las representaciones espaciales que conforman la imaginación geopolítica china y cómo se proyectan éstas en su relacionamiento con América Latina y el Caribe.

\section{La política exterior de China}

Los principios que orientan la política exterior china desde la instauración de la República Popular en 1949 hasta la actualidad tienen sus bases en la impronta de sus 
dos principales líderes políticos: Mao Zedong, quien ejerce el poder hasta 1976, y Deng Xiaoping que lo sucede en 1978. Como sostiene Yang:

[E]n estos dos líderes chinos está la fuente de las respuestas que las autoridades chinas han dado a la reciente realidad china y mundial en que se cruzan el confucianismo y el modernismo, el conservadurismo y la revolución, el conformismo y el reformismo, la democracia y la dictadura, el capitalismo y el socialismo, la guera fría y la paz mundial, el proteccionismo y la globalización, la tendencia expansionista y un mundo multipolar (2005: 20).

En el periodo de Mao, entre el triunfo de la Revolución y el reingreso en la Organización de Naciones Unidas en 1971, China se replegó parcialmente de la escena internacional como consecuencia del bloqueo impuesto por EE UU, relacionándose principalmente con países del campo socialista. En esas dos décadas, su política exterior tuvo una fuerte impronta internacionalista y antiimperialista (Yang, 2005). Con el inicio del acercamiento con EE UU, marcado por la visita del Presidente Nixon a Beijing en 1972, comenzó una nueva etapa en la que se ampliaron las relaciones diplomáticas a partir del reconocimiento de la República Popular China por parte de una gran cantidad de países.

Tras la llegada al poder de Deng Xiaoping, la impronta internacionalista y la idea de una amenaza proveniente del exterior fue reemplazada por un énfasis en el interés nacional como principio rector de la política económica y de la política exterior. Según Yang, en este periodo "crece en la cúpula china la conciencia de que la amenaza real para el desarrollo de China no viene del exterior, sino que está en el atraso económico" (2005: 35). El restablecimiento pleno de las relaciones con EE UU en 1979 se justifica en la lectura de Deng de que era necesario apartar cuestiones ideológicas y avanzar en las relaciones económicas con EE UU para impulsar el desarrollo económico nacional. No obstante, esto no implicó que las cuestiones ideológicas desaparecieran de los discursos oficiales que guían la política exterior incluso en la actualidad. Por el contrario, persisten de manera explícita elementos como la lucha contra la hegemonía, la impronta del marxismo y la percepción de China como un país en "vías de desarrollo" que comparte un destino común con los países del Tercer Mundo (Yang, 2005: 38).

En el marco del fin de la Guerra Fría, las condiciones para la alianza entre China y EEUU cambiaron, ya que hasta entonces ésta había girado en torno al esquema de polarización entre EEUU y la Unión Soviética (Yang, 2005; Gaspar, 2005). A partir de este periodo, China dejó de ser una potencia por causa de su posición en la organización bipolar del mundo pasando a ser "una gran potencia por mérito propio" (Gaspar, 2005: 57). Su relevancia en el escenario internacional está vinculada a la expansión de su economía y un mayor protagonismo en instituciones internacionales ${ }^{3}$ (Ríos, 2005).

Por otro lado, la represión violenta del movimiento de protesta en Tiananmen en junio de 1989 trajo como consecuencia sanciones de Occidente que repercutieron en

3 Algunos ejemplos que influyen en la relación con ALC son: la incorporación como Estado observador al Banco Interamericano de Desarrollo (BID) en 1991, el ingreso a la Organización Mundial de Comercio (OMC) en 2001 y la incorporación como observador permanente en la Organización de Estados Americanos (OEA) en 2004. 
la estrategia de desarrollo china. Es en ese contexto en el que China da inicio a una nueva etapa en las relaciones políticas y económicas con países de ALC, en el marco de la búsqueda de aliados internacionales al tiempo que promovía la organización de bloques regionales en Asia, entre otros la Organización para la Cooperación de Shanghai (Yang, 2005).

El objetivo prioritario que orienta la política interna y externa es la materialización del sueño de la gran revitalización de la nación china (PCCH, 2012; 2017), cimentado en una narrativa histórica que contempla:

- el pasado de grandeza de una civilización de más de cinco milenios de antigüedad,

- un periodo de oscurantismo y atraso como consecuencia de las guerras del Opio del siglo XIX, y

- la gesta de liberación iniciada con la fundación del Partido Comunista de China y retomada luego por la Revolución de 1949.

Estos componentes esenciales de la autopercepción de China explican los ejes de su política exterior. China se ve a sí misma como un país que fue víctima de la humillación por parte de países occidentales y que se reconstruyó a costa de esfuerzo alcanzando un importante grado de desarrollo, aún inconcluso, enraizado en sus principales fortalezas: la dimensión de su población, su cultura y su civilización milenaria, su poderío en armamento nuclear y su condición de miembro con poder de veto en el Consejo de Seguridad de Naciones Unidas (Gaspar, 2005).

El principio fundamental que guía la política exterior de China desde la segunda mitad del siglo XX es el de la coexistencia pacífica. Si bien su origen se remonta a la era de la geopolítica ideológica, su impronta continúa vigente en la actualidad como "columna vertebradora de los demás factores que determinan su actuar internacional" (Ríos, 2005: 13). La coexistencia pacífica forma parte de un conjunto de máximas formuladas en 1953, en el marco del conflicto indochino, por el primer ministro Zhou Enlai que posteriormente fueron incorporadas en documentos oficiales de política exterior. Conocidos como los Cinco principios persisten como la referencia central de todo el desarrollo posterior de la política exterior reactualizándose en función del contexto histórico. Según la formulación inicial, éstos son: respeto mutuo de la soberanía e integridad territorial; no agresión; no injerencia en los asuntos del otro; igualdad y beneficio mutuo; y coexistencia pacífica.

\subsection{El posicionamiento de China en el mundo del siglo XXI: la doctrina del "desarrollo pacífico"}

En los códigos geopolíticos que orientan la política exterior china en el siglo XXI subyacen supuestos geográficos que asocian al mundo con un territorio dividido en pares contrapuestos: Norte-Sur y países desarrollados-países en vías de desarrollo. Desde esta lógica binaria, China se autodefine como un país en vías de desarrollo que apunta a tejer alianzas de cooperación y posicionarse como líder del espectro de países no desarrollados que forman el eje del Sur global.

En el documento Posición china para la cooperación Sur-Sur, publicado en 2003, se hace un llamamiento a profundizar la cooperación entre los países de vías de desarrollo destacando las potencialidades que tendría este tipo de alianza para el 
"beneficio mutuo" y "desarrollo común”. Sin hacer referencia explícita a ningún país o grupo de países en específico, el imaginario de fondo contiene dos justificaciones:

I. El de una alianza del Sur para enfrentar a un Norte que hasta el momento tiene mayor incidencia en la determinación de las reglas de funcionamiento del sistema internacional con el objetivo de "participar activamente en la elaboración de «Reglas de Juego» en el terreno económico internacional, impulsar la reforma de la estructura económica, financiera y comercial internacionales" (MOFA, 2003).

II. La globalización económica es una realidad exterior cuyo devenir inevitable presenta desafíos que los países en vías de desarrollo sólo podrán enfrentar de manera conjunta: "Sólo uniéndose como un solo hombre, los países en vías de desarrollo podrán elevar su status en el dialogo Sur-Norte y defender al máximo sus propios intereses en el proceso de la globalización" (MOFA, 2003).

El ingreso de China a la Organización Mundial del Comercio (OMC) en 2001 tras más de una década de negociaciones constituyó un hito que reafirmó el modelo de apertura económica iniciado a fines de la década de 1970. En el proceso de construcción de una "economía de mercado socialista", el ingreso a la OMC supuso importantes cambios en materia de regulación económica ${ }^{4}$ que permitieron que el país se configurara de manera creciente como un actor influyente en el sistema de comercio mundial (Adhikar \& Yang, 2002). Con una economía en expansión, China fue consolidándose cada vez más como una potencia emergente con perspectiva de ampliar su rol en la escena internacional. Pero es preciso señalar que la importancia de la economía china no se debe sólo a su tamaño. Más allá de que el volumen del Producto Bruto Interno (PBI) la posicione como la segunda a nivel mundial, el enorme incremento del nivel de intercambios con EE UU que tuvo lugar en las últimas décadas hace que en la actualidad ambos países mantengan una relación de "mutua dependencia económica" (Correa López \& González García, 2005: 108).

El espectacular ritmo de crecimiento de su economía y su consolidación como potencia emergente en la escena internacional son los factores sobre los que se gestó el surgimiento de tesis que reactualizan el imaginario del "peligro amarillo" o la "amenaza china" que comenzaron a circular en ámbitos académicos occidentales y de Japón ${ }^{5}$. La supuesta amenaza se sustenta en gran parte en la presunción de que el país asiático estaría siguiendo una de las máximas de Deng Xiaoping basada en la estrategia de ocultación del poder para acumular fuerzas antes de pasar a una estrategia ofensiva (Bustelo, 2005; Gaspar, 2005). En opinión de Chun, teniendo en cuenta la historia y tradición no expansionista del país asiático, "la propaganda sobre la «amenaza china» carece de base" (2013: 19). No obstante, la respuesta a las tesis

4 Por ejemplo, EEUU le otorgó de manera permanente el status de nación más favorecida (NMF) que anteriormente dependía de la aprobación anual del Congreso. Además, otros socios comerciales debieron eliminar parte de las restricciones a los productos chinos para encuadrar los intercambios en la regulación vigente en la OMC (Adhikari \& Yang, 2002).

5 Estas tesis continúan desarrollándose en la actualidad. Por ejemplo, el geopolítico americano Robert Kaplan (2010) en un artículo titulado "La geografía del poder chino" retoma el planteamiento clásico de Mackinder (1904 [2011]) para señalar que, dadas sus características geográficas, China es un poder "tanto terrestre como marítimo" cuya expansión podría constituir un "peligro amarillo". 
anti-chinas fue la elaboración y difusión de la teoría del "ascenso pacífico", , desarrollada por académicos chinos durante el gobierno de Hu Jintao (Bustelo, 2005; Rocha Pino, 2006; Lee, 2013). Con ello, China comenzó la construcción simbólica y proyección al exterior de una imagen de potencia no amenazante cuyo principal interés es su propio desarrollo y modernización en condiciones de cooperación con el resto del mundo. Vale la pena detenerse en las afirmaciones realizadas por el intelectual chino Zheng Bijian en el Foro Bo'ao para Asia del año 2003, en las que enuncia tres ideas centrales que luego serán retomadas en todos los códigos geopolíticos emitidos por el gobierno: 1) ascenso/desarrollo pacífico, 2) socialismo con características chinas (lo cual incluye referencias al confucianismo como complemento de la retórica del marxismo-leninismo) y 3 ) la visión sobre la globalización económica:

Desde los últimos 25 años, a partir de la instrumentación de su reforma y su apertura al exterior, China ha seguido un nuevo patrón estratégico que no sólo considera sus condiciones nacionales, sino que también avanza con el correr de los tiempos. Este nuevo patrón estratégico es el ascenso pacífico de China, a través del cual se construye de manera independiente (soberana) el socialismo con características chinas, mientras que participamos, en lugar de rechazarla, en la globalización económica (Bijian, cit. en Rocha Pino, 2006: 707).

Estas definiciones, que podríamos situar en el ámbito de la geopolítica formal o académica, se retoman luego como referencia para la geopolítica práctica. El concepto de "ascenso pacífico" pasó a integrar desde 2003 el discurso oficial de China siendo utilizado tanto en las intervenciones públicas de los dirigentes políticos como en documentos diplomáticos. Pero pronto, a mediados de 2004, el término "ascenso" fue reemplazado por el de "desarrollo", luego de que el primero suscitara debates en torno a una posible interpretación vinculada a una pretensión expansionista o neocolonial (Rocha Pino, 2006).

En los años posteriores, el desarrollo pacífico se convirtió en la doctrina principal de la política exterior china. En el informe que el presidente Ju Hintao presentó ante el XVIII Congreso del Partido Comunista de China en el año 2012, el desarrollo pacífico es uno de los ejes principales, y además se introduce una perspectiva temporal que da cuenta de la visión estratégica integral del país (Peng, 2013). Allí se establecen metas de corto, mediano y largo plazo, para alcanzar mediante el "socialismo con particularidades chinas" una sociedad "modestamente acomodada" que selle la transformación total del país siguiendo el legado de Mao Zedong y Deng Xiaoping (PCCH, 2012).

En el documento Libro Blanco: Desarrollo Pacífico de China, publicado en 2011, el gigante asiático se asume como el "país en vías de desarrollo" más grande del mundo. No obstante, se enfatiza la plena identificación con los intereses de los países del "Tercer Mundo" y la apuesta por un sistema internacional equitativo

6 La difusión en Occidente se concretó en 2005 con la aparición del texto China's Peaceful Development Road adoptado por el Consejo de Estado en el mes de diciembre. En los meses previos, la revista Foreign Affairs había replicado un artículo donde Zheng Bijian (2005), a quien se atribuye principalmente la formulación de la teoría, fundamentaba por qué China adoptaba el ascenso pacífico como estrategia de desarrollo distinguiéndolo del ascenso de otras potencias occidentales como la Alemania de la época de Bismark (Rocha Pino, 2006). 
donde primen la armonía y la paz en las relaciones multilaterales (MOFA, 2011). El documento inicia con un preámbulo acerca de los crecientes interrogantes del mundo en el contexto de la globalización, a los que se responde con un mensaje de no rivalidad que resalta el rumbo adoptado:

China, descansando en su tradición histórica y cultural de varios milenios, en su comprensión sobre la esencia de la globalización económica, comprensión sobre los cambios de las relaciones internacionales y la configuración de la seguridad internacional en el siglo XXI, comprensión de los intereses conjuntos y el valor conjunto de la humanidad, ha escogido con toda seriedad el desarrollo pacífico, la cooperación de beneficio mutuo como canal básico para hacer realidad la modernización del país, participar en los asuntos internacionales y tratar las relaciones internacionales. La práctica de varios decenios corrobora que el camino de desarrollo pacífico seguido por China es correcto. No hay ninguna razón para cambiarlo (MOFA, 2011).

El Libro Blanco está estructurado en cinco apartados: 1) Apertura del camino de desarrollo pacífico de China; 2) Metas generales del desarrollo pacífico de China; 3) Orientación y políticas exteriores del desarrollo pacífico de China; 4) El desarrollo pacífico de China es una opción necesaria de la historia, y 5) Significado mundial del desarrollo pacífico de China. En ellos se parte de un relato de la historia del país que se reconstruye siempre en "espejo" de la historia de Occidente. El siglo que va entre las guerras del opio y el triunfo de la Revolución de 1949 se caracteriza como un periodo oscuro que sumió al país en el atraso económico. La apertura de la economía y el imperativo del desarrollo se perciben como elementos determinantes para alcanzar la modernización. Los ejes centrales que recorren el texto son:

- La globalización como nuevo escenario geopolítico que importa tanto oportunidades como desafíos para los Estados. De estos desafíos y oportunidades surge la necesidad de tejer lazos de cooperación y multilateralidad: "La globalización económica es una importante tendencia que influye en las relaciones internacionales. Los países con distintos sistemas, distintos tipos y distintas etapas de desarrollo se dependen mutuamente [sic], sus intereses se mezclan y se armonizan, formando una comunidad de destino en que «en ti estoy y en mí estás». La humanidad no puede soportar más guerras mundiales. Los enfrentamientos y el antagonismo entre las potencias no pueden sino conducir a la derrota de una y otra parte y provocar heridas entre ellas" (MOFA, 2011).

- La apertura como modelo de desarrollo económico. Si bien se asume la participación en la globalización económica también se enfatiza la independencia y autodeterminación de su política estatal. China "considera la reforma y apertura como una medida política estatal básica, combina la reforma interior con la apertura al exterior, integra la persistencia en la independencia y la autodeterminación con la participación en la globalización económica, [...] se incorpora en una actitud abierta al mundo, extiende constantemente la amplitud y la profundidad de la apertura al exterior, refuerza los intercambios y la cooperación con los diversos países del mundo, perfecciona el sistema económico tipo abierto de acción conjunta interior-exterior, beneficio 
mutuo, seguro y altamente eficaz. No cerrará nunca la puerta de la apertura al exterior y el nivel de la apertura no podrá sino ser cada vez más alto" (MOFA, 2011).

- La paz y la armonía como una forma novedosa de relacionamiento en el sistema interestatal. En lo que parece un mensaje a Occidente, el gobierno chino enfatiza que el desarrollo pacífico de su país no supone en forma alguna una amenaza al desarrollo de otros países, en tanto "respeta el derecho de los pueblos de los diversos países de optar independientemente, su sistema social y camino de desarrollo, no interviene en los asuntos internos ajenos, se opone a que los grandes afrenten a los pequeños, los poderosos a los débiles y se opone al hegemonismo y a la política del uso de la fuerza. Persiste en dar solución a las contradicciones y discrepancias mediante la búsqueda de puntos comunes, dejando a un lado las discrepancias, y el diálogo y la consulta. No impone su voluntad a otros" (MOFA, 2011).

- Renuncia a la pretensión de hegemonía que caracterizó la geopolítica en el siglo XX: "El desarrollo pacífico de China ha roto con la modalidad tradicional del sobresalir de países grandes en el sentido de que «cuando un país se hace poderoso necesariamente será hegemónico» [...] China hace activos aportes a la paz y el desarrollo mundiales, no practicará ni invasión ni expansión, nunca disputará por la hegemonía ni será hegemónico, siempre será una fuerza firme en la defensa de la paz y la estabilidad mundiales y regionales" (MOFA, 2011).

- La centralidad del Estado y su soberanía territorial como actor de la política mundial. La comprensión y participación en los procesos de globalización económica no implica en el imaginario chino una disminución del poder del Estado: "China persiste en defender los intereses clave del Estado. Estos intereses abarcan: la soberanía estatal, la seguridad estatal, la integridad territorial, la unificación del país, el sistema político estatal definido en la Constitución de la República Popular China y la estabilidad de la situación social en su conjunto, garantías básicas para el desarrollo socioeconómico sostenible" (MOFA, 2011).

- La reafirmación de un nuevo concepto de seguridad del cual se deriva una política de seguridad defensiva. El nuevo concepto de seguridad chino fue desarrollado en el contexto pos Guerra Fría y se basa fundamentalmente en la idea de que los procesos de globalización generan una mayor interdependencia económica que hacen necesaria la cooperación en materia de seguridad para salvaguardar los intereses compartidos ${ }^{7}$. Se trata de "la propuesta china para crear un orden alternativo, sin necesidad de establecer una confrontación con otras potencias" (Rocha Pino, 2006: 698). Al respecto, en el

\footnotetext{
Rocha Pino señala que "durante su discurso ante la 52 Sesión de la Asamblea General de la ONU, en octubre de 1997, [el Ministro de Exteriores] Qian expuso los cuatro puntos que componían la propuesta china sobre seguridad para la posguerra fría: 1) Los sistemas de seguridad basados en las alianzas militares o la carrera armamentista se habían vuelto insuficientes para conservar la paz. 2) Las relaciones entre los Estados debían basarse en los cinco principios de la coexistencia pacífica [...] 3) La economía internacional debía convertirse en una base para la seguridad regional y global, en el marco del beneficio mutuo y las prácticas entre iguales. 4) Todos los países deberían crear mecanismos de consulta y cooperación en el área de la seguridad, e incrementar el entendimiento y la confianza mutuos con el fin de resolver sus conflictos de manera pacífica" (2006: 695-696).
} 
documento se deja asentado que: "China aboga por un nuevo concepto de seguridad que se caracteriza por la confianza mutua, el beneficio recíproco, la igualdad y la coordinación y busca la coronación de la seguridad integral, seguridad conjunta y seguridad cooperativa [...] El objetivo fundamental de la modernización del ejército chino es defender la soberanía estatal, la seguridad y la integridad territorial y garantizar los intereses del desarrollo estatal [...] China no hará ni intentará hacer carrera armamentista con ningún otro país, y no constituirá una amenaza militar para ningún otro país. China persiste en «No atacaremos a menos que seamos atacados» y aboga por dar solución pacífica a las disputas y focos candentes internacionales. China concede atención al reforzamiento de los intercambios militares internacionales, fomenta la cooperación de seguridad internacional y regional, y se opone a toda forma del terrorismo" (MOFA, 2011).

Desde el inicio de la presidencia de Xi Jinping en 2013, China se encuentra en una fase de consolidación de su rol protagónico en la escena internacional. Con mayor capacidad de liderazgo que sus antecesores (Xu Jintao y Jiang Zemin), el actual mandatario se perfila como el sucesor simbólico de los dos grandes referentes chinos, Mao Zedong y Deng Xiaoping. Sin abandonar las líneas maestras y las metas de desarrollo trazadas durante las décadas precedentes, la presidencia de Xi comporta cierto halo novedoso en la interpretación de la situación nacional y en la dirección de la política exterior. En el informe presentado ante el XIX Congreso del $\mathrm{PCCH}$, titulado Por el logro del triunfo definitivo en la culminación de la construcción integral de una sociedad modestamente acomodada y por la conquista de la gran victoria del socialismo con peculiaridades chinas de la nueva época, Xi Jinping da por alcanzado el objetivo de elevar el nivel de vida de la población con miras a construir una sociedad "modestamente acomodada" e introduce la noción de "nueva época" para referirse a una nueva fase en la construcción del "socialismo con particularidades chinas". Esta nueva época plantea desafíos novedosos a lo interno y a lo externo. En el ámbito nacional supone un reajuste en la interpretación de la contradicción principal de la sociedad china:

Con la entrada del socialismo con peculiaridades chinas en la nueva época, la contradicción principal de la sociedad de nuestro país ha pasado a ser la que existe entre la creciente demanda del pueblo de una vida mejor y el desarrollo desequilibrado e insuficiente. Habiendo resuelto de modo sólido el problema de vestir y alimentar a sus más de mil millones de habitantes, nuestro país ha alcanzado en general una vida modestamente acomodada y dentro de poco culminará la construcción integral de una sociedad modestamente acomodada; el pueblo plantea demandas cada día más amplias en su búsqueda de una vida mejor, formulando no solo exigencias más elevadas en lo referente a la vida material y cultural, sino también exigencias cada vez más numerosas en varios ámbitos, entre ellos los de la democracia, el imperio de la ley, la equidad, la justicia, la seguridad y el medio ambiente (PCCH, 2017).

Una novedad significativa es el incremento en la era Xi Jinping de las referencias a la defensa de los intereses nacionales, lo cual dota a la política exterior del actual mandatario una impronta más asertiva y proactiva (Esteban, 2017) que la de sus 
antecesores, en una tendencia que podría acentuarse durante los próximos años acompañando la consolidación del rol cada vez más preponderante de China en el escenario económico internacional, cuya expresión inmediata es la Iniciativa de la Franja y la Ruta": "China de ninguna manera se desarrollará a costa de los intereses de otros países, pero tampoco renunciará a sus derechos e intereses legítimos, por lo que nadie debe ilusionarse con la posibilidad de que China trague el amargo fruto del menoscabo de sus intereses" (PCCH, 2017).

Si bien se mantienen las líneas de la doctrina del desarrollo pacífico, la política de seguridad defensiva y la primacía de los intereses estatales, en el informe se establece un nuevo punto de partida histórico en la construcción de la política de defensa nacional y se aboga por la modernización de la teoría militar para adaptarla al estadio actual del desarrollo nacional. El objetivo declarado es tener un ejército de "primer orden mundial", "preparado para combatir" y para "detener guerras o ganarlas" (PCCH, 2017).

Así, en la lectura de Xi, la "nueva época" en la construcción del socialismo con particularidades chinas sitúa a China como un país con mayor "responsabilidad" en la escena internacional. En el Informe, China se asume como referente mundial en la construcción de la paz, como un país que contribuye notablemente al desarrollo global y que defiende el orden internacional de la globalización económica:

China seguirá desplegando su papel de gran país responsable y participará con dinamismo en la reforma y la construcción del sistema de la gobernanza global, aportando incesantemente su propia sabiduría y fuerza [...] Mancomunando esfuerzos para superar las dificultades, tenemos que promover la liberalización y facilitación del comercio y la inversión, e impulsar la globalización económica hacia un desarrollo en el que la apertura, la inclusión, los beneficios de alcance general, el equilibrio y el ganar-ganar tengan un nivel más alto (PCCH, 2017).

En definitiva, en la imaginación geopolítica china están presentes elementos de los principios básicos de la imaginación geopolítica moderna que se combinan con particularidades de la cultura e historia del país dando lugar a una particular forma de ver el mundo. El imaginario de la globalización económica es el eje central en la política exterior china en el siglo XXI. De esta representación se deriva una concepción del mundo imaginado como un todo interdependiente en el que para alcanzar el desarrollo económico — principal interés nacional- la opción estratégica es la cooperación y la apuesta por la multilateralidad ${ }^{9}$ como forma de relacionamiento en la política mundial. La aceptación de la globalización económica como un proceso imparable no implica que los Estados, al menos el chino, dejen de ser los actores centrales sobre los que pivotan las relaciones internacionales. A la vez, el imaginario de la globalización tiene implicaciones en el concepto de seguridad. En el escenario abierto con la finalización de la Guerra Fría, la "lucha por la supremacía" —entendida como un enfrentamiento inevitable entre potencias por dominar el mundo-

\footnotetext{
Ver CEPAL (2018).

9 En los años posteriores a la finalización de la Guerra Fría, cobró auge en los discursos y códigos geopolíticos la tesis de la multipolarización, que durante la presidencia de $\mathrm{Hu}$ Jintao fue parcialmente reemplazada por la noción menos belicosa de multilateralismo. No obstante, el discurso multipolar continúa en uso alternándose de manera pragmática con el del multilateralismo (Rocha Pino, 2006).
} 
habría quedado obsoleta, pues al hacer la globalización económica más interdependientes a las economías de distintos puntos del globo lo que se impone es la cooperación para salvaguardar los propios intereses. De ahí que China enfatice en sus códigos geopolíticos la doctrina del desarrollo pacífico rechazando la carrera armamentística y cualquier otra forma de pretensión hegemónica que pudiera llevar a una estrategia de confrontación abierta entre potencias.

\section{América Latina y el Caribe en la imaginación geopolítica de China}

Desde un punto de vista histórico, las relaciones entre China y los países de América Latina y el Caribe tuvieron, desde la proclamación de la República Popular en 1949, un carácter cambiante en función del contexto internacional. En una primera fase, a raíz del bloqueo impulsado por EE UU, las Naciones Unidas reconocieron como legítimo al gobierno de Taiwán. En ese contexto, los países de ALC no establecieron relaciones diplomáticas con la República Popular China ${ }^{10}$. A partir de la década de 1970 , con el reingreso en la ONU de China y en el contexto de un mayor acercamiento con EE UU, los países de ALC comenzaron a establecer vínculos diplomáticos con el país asiático. Desde la década de 1990, los vínculos comenzaron a ser más estrechos. En el contexto de las sanciones de Occidente por la represión de Tiananmen, China comenzó a buscar alianzas en la región latinoamericana y caribeña, sobre todo en el área económica. Con su ingreso en la OMC en 2001, las relaciones económicas se intensificaron adquiriendo mayor dinamismo y volumen ${ }^{11}$.

Los códigos geopolíticos de China en su relacionamiento con América Latina y el Caribe toman como referencia la doctrina del desarrollo pacífico y los cinco principios de coexistencia pacífica que orientan toda su política exterior. En el Documento sobre la política de China hacia América Latina y el Caribe, tanto en su versión original de 2008 como en la actualización del 2016, el gobierno chino explicita los objetivos de su política hacia la región y establece ciertas "reglas de juego" que deben guiar las relaciones: cooperación, beneficio recíproco y desarrollo compartido. Como señala Peng la promoción del desarrollo conjunto constituye el principal elemento de la "ideología ganar-ganar" que sustenta el concepto chino de armonía mundial (2012: 142). El texto de 2008 está estructurado en cinco apartados: 1) Posición y papel de América Latina y el Caribe; 2) Relaciones entre China y América Latina y el Caribe; 3) Política de China hacia América Latina y el Caribe; 4) Fortalecimiento de la Cooperación Omnidireccional entre China y América Latina y el Caribe, y 5) Relaciones entre China y las organizaciones regionales latinoamericanas y caribeñas.

En el documento, la imaginación geopolítica de China se proyecta sobre las relaciones con América Latina y el Caribe. Un primer aspecto a destacar es que la región aparece como un todo indiferenciado sin contemplar la diversidad de realidades y

10 Un aspecto relevante en la política exterior de China es el principio de "una sola China" con el cual se enfatiza la importancia de unificación territorial y la postura en el conflicto con Taiwán. En la actualidad 12 de los 22 países que reconocen a Taiwán como Estado se encuentran en la región de América Latina y el Caribe.

11 Una revisión actualizada y exhaustiva del estado de los vínculos económicos y políticos diferenciados por casos nacionales puede consultarse en CEPAL $(2015,2018)$ y en Bonilla \& Millet (2015). 
proyectos políticos, económicos y de integración que coexisten en su interior ${ }^{12}$. De manera general, ALC es identificada desde la perspectiva de China como una zona de paz cuya extensión geográfica y recursos naturales suponen un gran potencial de desarrollo, y a la vez como un conjunto de países en "vías de desarrollo" con los cuales la alianza es "natural" dada las fases similares de desarrollo y posicionamiento en el escenario internacional. En la tercera parte del documento se explicitan los tres objetivos generales de la política china hacia la región:

1. Construir un vínculo de "confianza política y consenso estratégico» bajo los cinco principios de coexistencia pacífica. Para ello, China se compromete a tratar "en pie de igualdad y respeto mutuo" a los países de ALC.

2. Generar una asociación de cooperación en lo económico y comercial con el objetivo de alcanzar el "desarrollo común” bajo los principios del "beneficio recíproco y la ganancia compartida".

3. Aumentar los intercambios en el área cultural "con el propósito de aprenderse [sic] mutuamente las experiencias provechosas en promoción conjunta del desarrollo y progreso de la civilización humana” (MOFA, 2008).

Autodefiniéndose como "el país más grande en vías de desarrollo", el objetivo parece ser generar consenso en el conjunto de los países en vías de desarrollo acerca de la doctrina de desarrollo pacífico, en particular en lo que atañe a las relaciones interestatales que deberían basarse en la cooperación y el multilateralismo. La imaginación geopolítica china percibe al mundo como dividido en dos: países desarrollados y países en vías de desarrollo. La estrategia que subyace es posicionarse como vocero del segundo grupo, donde también posiciona a ALC, para establecer alianzas que permitan ampliar el poder de decisión en la definición de las "reglas de juego" de la política mundial. Así, en el Libro Blanco el eje cooperación en asuntos internacionales declara que:

El Gobierno chino tiene la disposición de seguir fortaleciendo la coordinación y colaboración con los países latinoamericanos y caribeños en los asuntos internacionales [...] apoyándose mutuamente en temas trascendentales que atañan a la soberanía estatal e integridad territorial de una y otra parte. La parte china está dispuesta a dedicarse, junto con los países latinoamericanos y caribeños, al fortalecimiento del papel de las Naciones Unidas, la promoción del desarrollo del orden político y económico internacional hacia una dirección más justa y razonable, el impulso de la democratización de las relaciones internacionales y la defensa de los derechos e intereses legítimos de los países en desarrollo. China es partidaria de que los países latinoamericanos y caribeños jueguen un papel más importante en la arena internacional (MOFA, 2008).

El último punto del Libro Blanco hace referencia a las relaciones entre China y los organismos regionales de ALC con un llamamiento a fortalecer las instancias de integración como un modo de aumentar la influencia en la escena internacional.

12 Por ejemplo, como señalan (Preciado \& Uc, 2015) en América Latina y el Caribe "existen dos importantes sendas de integración regional con perfiles divergentes, e incluso conflictivos": por un lado, UNASUR, ALBA y MERCOSUR, y por otro, la Alianza del Pacífico. 
Hasta el año 2015 no se había configurado una instancia de intercambio entre China y ALC como región. Las relaciones eran o bilaterales o con organismos subregionales como la Alianza del Pacífico del cual China es miembro observador o con el Mercosur a quien elevó un proyecto de Tratado de Libre Comercio en 2012. En el marco de la CELAC ${ }^{13}$, en 2014 se aprobó la creación del Foro CELAC-China que se reunió por primera vez en enero 2015 en Beijing.

Del análisis de los códigos geopolíticos de China se desprende que su política exterior consiste en formas de poder blando (Rodríguez, 2013; Lee, 2013), rechazando cualquier pretensión expansionista o de dominio territorial más allá de sus fronteras. El interés mayor es generar consenso en torno a los principios que sustentan su particular imaginación geopolítica. Estos son: desarrollo pacífico, globalización sin renunciar a la soberanía estatal, multilateralismo, y nuevo concepto de seguridad basado en la cooperación internacional. En los documentos oficiales, la hegemonía se percibe como dominación coercitiva, y se hace explícito que el interés de China no se relaciona con una pretensión de convertirse en una "potencia hegemónica". Por ejemplo, en ocasión de la celebración del sesenta aniversario de los Cinco Principios, el gobierno de China declara que:

Bajo estas circunstancias, [las del mundo actual] el espíritu de los cinco principios de coexistencia pacífica cobra cada vez mayor relevancia real. China se opone a la teoría de que los países poderosos siempre buscan la hegemonía. China seguirá invariablemente en el camino de desarrollo pacífico y espera con toda sinceridad que todos los demás países también se adhieren a este derrotero. China jamás impondrá nuestra voluntad a los ajenos ni jamás procurará la hegemonía con lo fuerte que llegaría a ser [sic] (MOFA, 2003).

Pero la hegemonía también puede entenderse como la búsqueda de construcción de consensos. Tal como sostiene Agnew (2005b), la hegemonía no es equivalente a primacía económica, política o militar. Desde una perspectiva gramsciana, la hegemonía puede asumirse como "la inscripción de los otros en el ejercicio propio del poder mediante el convencimiento, la atracción y la coerción de forma tal de que deberían desear lo que tú deseas". En consecuencia, se trata de un proceso dinámico "nunca completo y con frecuencia resistido" (2005b: 1-2). En el plano de la geopolítica, la hegemonía "se refiere a las normas y principios que regulan la política mundial" que surgen de la inscripción de una particular imaginación geopolítica en el conjunto del mundo (2005a: 90). De acuerdo a Agnew (2005a) la búsqueda de la supremacía es un fenómeno contingente que adquiere sentidos particulares en diferentes épocas. En el contexto actual, en parte por el impulso dado por EE UU durante la era de la geopolítica ideológica a la globalización económica, la búsqueda de la supremacía "no parece una receta adecuada para triunfar" (Agnew, 2005b: 98). Por el contrario, la interdependencia económica y la idea de "destino global común" generan mayores incentivos para la cooperación y el multilateralismo, movidos por el

13 La CELAC (Comunidad de Estados Latinoamericanos y Caribeños) es una instancia de diálogo intergubernamental que agrupa a los 33 países de ALC. En términos políticos la creación de la CELAC en 2011 marcó una diferencia central con la Organización de Estados Americanos (OEA), única instancia de encuentro de todos los países de ALC: el reemplazo de EE UU por Cuba. 
interés de cada Estado de asegurarse que los demás adscriben a las reglas de juego en el sistema internacional (Agnew, 2005a: 96).

Del análisis de los códigos geopolíticos de China se desprende que la estrategia de su política exterior es la utilización de formas de convencimiento para inscribir su particular imaginación geopolítica en el funcionamiento del sistema interestatal y en particular con la región de ALC. Esto puede pensarse como una forma de resistencia contrahegemónica a lo que consideran un sistema internacional no equitativo, donde los países "en vías de desarrollo" deberían ocupar posiciones de mayor relevancia en condición de igualdad con el resto. De ahí la apelación a la "democratización en las relaciones internacionales" para alcanzar un "sistema de comercio multilateral justo, abierto, racional y libre de discriminación, posibilitando que los frutos de la globalización económica beneficien a todos los países del mundo" (MOFA, 2011).

En la relación con América Latina y el Caribe, la búsqueda de hegemonía china entendida como el interés de posicionarse como "fijadora de normas" (Agnew, 2005a: 90) y generar consenso en torno a su particular imaginación geopolítica se refleja en los acuerdos suscritos en el marco del Foro CELAC-China. La Declaración de Beijing, de 2015, se sustenta en los principios ya enunciados en el Documento sobre la política de China hacia América Latina y el Caribe sin grandes variaciones, por lo cual en la práctica se trata de la ratificación por parte de los países de ALC de la "forma de ver el mundo" de China, o del "Consenso de Beijing" (Cooper R., 2004) y su particular concepción sobre la relación con ALC. Los principales acuerdos que establece la Declaración ratifican la visión de China plasmada en el Libro Blanco del desarrollo pacífico: cooperación integral entre países en vías de desarrollo, multilateralismo, democratización de las relaciones internacionales y beneficio mutuo (FCC, 2015). Más en concreto:

China y los Estados latinoamericanos y caribeños, en su condición de países en vías de desarrollo y economías emergentes, constituyen relevantes fuerzas para la consecución de la paz mundial y la prosperidad, así como la promoción del multilateralismo, de un mundo multipolar y una mayor democratización de las relaciones internacionales. [...] Ambas partes expresan su disposición de intensificar el diálogo y la colaboración en los asuntos regionales y globales de interés común, reforzar su colaboración en los temas de trascendencia global, fortalecer la voz de los países en vías de desarrollo en los organismos decisorios multilaterales y continuar contribuyendo positivamente a la paz, la estabilidad, el desarrollo y la prosperidad en el mundo. [...] China y América Latina y el Caribe enfrentan retos de desarrollo similares y comparten una amplia convergencia de intereses comunes, reconociendo asimismo los retos concretos que enfrentan los Estados miembros de la CELAC menos desarrollados. Coincidimos en que nuestra relación constituye una importante oportunidad para lograr el desarrollo mutuo. [...] Promover la cooperación integral, sustancial y de beneficio mutuo es una prioridad (FCC, 2015).

A diferencia del Libro Blanco de 2008, en el cual se identifican las áreas prioritarias para consolidar una "cooperación integral", tanto en la Declaración de Beijing como en el Plan de Cooperación CELAC-China 2015-2019 aparecen por primera vez alusiones a las diferencias internas en la región centradas en garantizar un trato 
igualitario y cooperativo que favorezca aún a aquellos Estados "menos desarrollados" proponiendo un "tratamiento especial" a los países del Caribe (FCC, 2015). Otro dato significativo que aparece en el texto de la Declaración de Beijing es el de la "no condicionalidad" como uno de los principios que guían la relación ALCChina. El mismo establece una diferencia que evoca los tipos de acuerdos de financiamiento que históricamente la región mantuvo con organismos de crédito del sistema internacional (Fondo Monetario Internacional, Banco Interamericano Desarrollo, Banco Mundial, entre otros). En la Declaración de Santiago, producto del II Foro CELAC-China, se ratifica el compromiso con la paz mundial y se introduce un enfático respaldo a los principios de la Carta de Naciones Unidas y su rol en el sistema de gobernanza global ante los desafíos actuales. A su vez se traza una hoja de ruta para continuar consolidando la relación de cara al futuro, principalmente en las áreas comercial, financiera y cultural, y por primera vez se habla de "explorar" la cooperación en temas de seguridad (FCC, 2018).

Los códigos geopolíticos que orientan la política exterior de China hacia ALC se sitúan no en el plano de la coerción sino en el uso de la capacidad de China en tanto potencia emergente de "diseñar la agenda político-económica de los demás, definiendo los modos de conducta apropiados y suministrando un marco para las relaciones interestatales al que los otros deben adaptarse si pretenden obtener el reconocimiento y las recompensas de las grandes potencias" (Agnew, 2005a: 12).

Asumiendo y participando activamente de las representaciones y prácticas que guían la política mundial —es decir del imaginario y las prácticas de la globalización económica que constituye en el contexto del siglo XXI una "hegemonía ideológica sin necesidad de un hegemón" (2005a: 12) - la política exterior de China presenta una mirada particular de "la manera en que funciona el mundo" (2005a: 11) en la que rechaza explícitamente toda política expansionista o de poderío militar abogando por el desarrollo pacífico, el multilateralismo y la cooperación en las relaciones interestatales. Al hacerlo, se posiciona como líder del conjunto de países en vías de desarrollo en una confrontación no belicosa con los países "desarrollados". En las relaciones que establece con ALC, a pesar de las diferencias evidentes en cuanto al poder económico o de influencia en las organizaciones del sistema internacional, China busca inscribir a los países de la región en una particular forma de concebir el escenario global: impulsa una alianza entre países en vías de desarrollo que en pie de igualdad pujan por ocupar posiciones de mayor relevancia en el diseño de las reglas de juego del sistema internacional a la vez que se fortalecen mutuamente mediante el beneficio compartido del desarrollo común.

\section{Conclusiones}

La imaginación geopolítica china tiene hondas raíces en la imaginación geopolítica moderna. La forma de ver el mundo de China se traduce en dos elementos centrales que articulan su política exterior: el imaginario de la globalización y el imperativo del desarrollo económico. En los códigos geopolíticos del siglo XXI, la globalización es entendida como un fenómeno principalmente económico, pero también político y de seguridad, que es indetenible y que genera una tendencia creciente de interdependencia en el sistema interestatal. De ahí se deriva una concepción del mundo visto como un todo interdependiente que es el fundamento de la doctrina del 
desarrollo pacífico y el sustento de sus puntos nodales: cooperación sur-sur, nuevo concepto de seguridad, ideología ganar-ganar (Peng, 2012) y multilateralidad como forma de resolver los conflictos en la política mundial.

En cuanto al imperativo del desarrollo, la política exterior china del siglo XXI se sustenta en el modelo económico impulsado desde fines de la década del setenta bajo el liderazgo de Deng Xiaoping. El proceso de apertura de la economía China estuvo orientado por una concepción de desarrollo económico que evoca la lógica binaria de la imaginación geopolítica moderna, específicamente la de la conversión del tiempo en espacio. Pero esta forma de entender y organizar el mundo, y su consecuencia lógica de que la solución al "atraso" pasaría por la repetición de la trayectoria europea surgió mucho antes: está presente incluso en los fundamentos del Gran Salto Adelante ${ }^{14}$ que promovía "alcanzar" a los países centrales en su desarrollo (Agnew, 2005a: 52).

Estos presupuestos, continúan vigentes en los códigos geopolíticos que orientan la política exterior de China en el siglo XXI, y particularmente la dirigida hacia América Latina y el Caribe. La lógica binaria "países desarrollados"-"países en vías de desarrollo" es uno de los fundamentos de la concepción de ALC como un aliado "natural" en la puja por incidir en la definición de las reglas de juego del sistema internacional.

En la imaginación geopolítica china, los Estados ocupan un rol central en la política mundial. Reconociendo la importancia de otros actores, como los poderes económicos transnacionales $\mathrm{u}$ organizaciones regionales-internacionales de las cuales forma parte e impulsa, los códigos geopolíticos de China enfatizan la defensa de la soberanía estatal en particular en cuanto a la unificación e integridad territorial. Si bien se reconoce al sector privado como un actor relevante, el actor central en las relaciones internacionales es el Estado y se convoca a la comunidad internacional a que "respete la estimación del pueblo chino respecto a la soberanía estatal, la seguridad, la integridad territorial y la estabilidad social" (MOFA, 2011).

En cuanto a la concepción del espacio existente más allá de las fronteras nacionales y los supuestos sobre las relaciones con otros actores en ese espacio, la imaginación geopolítica china presupone la idea de competencia entre Estados: "[e]n la comunidad internacional siempre existirán competencia y contradicciones" (MOFA, 2011), pero busca reformular este relacionamiento en una "competencia benigna", acentuando el multilateralismo justificado en la interdependencia creciente que crea la globalización económica.

Todos estos componentes se combinan con otros elementos culturales e históricos configurando una particular imaginación geopolítica que se proyecta en las relaciones con América Latina y el Caribe, en particular la concepción del mundo dividido según niveles de desarrollo donde los menos favorecidos deben aliarse y cooperar para conseguir beneficios mutuos. Autodefiniéndose como el país en vías de desarrollo más grande del mundo, China asume parte del imaginario occidental del institucionalismo neoliberal, rechazando toda forma de proteccionismo y situándose como defensora del orden internacional de la globalización económica, al tiempo que aboga por una forma de construcción de hegemonía basada en formas de poder blando con el objetivo de inscribir a sus aliados de ALC, y de otras regiones, en su

14 Plan económico impulsado por Mao Zedong entre 1958 y 1961. 
particular forma de ver el mundo. La relación dialéctica entre las representaciones de la imaginación geopolítica china y las prácticas concretas en las relaciones con los diferentes países que componen la región de ALC determinará en cada caso si se trata efectivamente de relaciones igualitarias de beneficio mutuo o relaciones asimétricas que reproduzcan patrones de dependencia. Para los países de ALC el desafío principal en el plano económico, tal como quedó de manifiesto en la celebración del II Foro CELAC-China ${ }^{15}$, es construir un proyecto de desarrollo propio en base a relaciones de intercambio no asimétricas, es decir, eludir que el relacionamiento con China se base meramente en la exportación de materias primas y la importación de valor agregado.

\section{Bibliografía}

Adhikari, R. \& Yang, Y. (2002) “¿Qué significará el ingreso en la OMC para China y sus socios comerciales?". Finanzas \& Desarrollo [En línea], 22-25. [URL: $<$ https://www.imf.org/external/pubs/ft/fandd/spa/2002/09/pdf/adhikari.pdf $>$. Consultado el 24 de mayo de 2016].

Agnew, J. (2005a) Geopolítica. Un re-visión de la politica mundial. Madrid: Trama Editorial. Agnew, J. (2005b) Hegemony. The New Shape of Global Power. Philadelphia: Temple Univesity Press.

Bijian, Z. (2005) "China's Peaceful Rise to Great-Power Status". Foreign Affairs, vol. 84, núm. 5, 18-24.

Bonilla, A. \& Millet, P. (eds.) (2015) China en América Latina y el Caribe: escenarios estratégicos subregionales. San José de Costa Rica: FLACSO-CAF.

Brzezinski, Z. (1998) El gran tablero mundial: la supremacía estadounidense y sus imperativos geoestratégicos. Barcelona: Paidós.

Bustelo, P. (2005) “El auge de China: ¿amenaza o «ascenso pacífico»?". Revista ARI (Real Instituto Elcano, Madrid) [En línea] [URL: $<\mathrm{http} / / \mathrm{bit} . l y / 2203 \mathrm{hYK}>$. Consultado el $24 \mathrm{de}$ mayo de 2016].

Cairo, H. (2005) "Prólogo. Re-pensando la geopolítica: la renovación de la disciplina y las aportaciones de John A. Agnew", en J. Agnew: Geopolitica. Una re-visión de la política mundial. Madrid: Trama Editorial, ix-xvi.

CEPAL (2015) América Latina y el Caribe y China. Hacia una nueva era de cooperación económica. Santiago de Chile: CEPAL.

CEPAL (2018) Explorando nuevos espacios de cooperación entre América Latina y el Caribe y China. Santiago de Chile: CEPAL.

Chun, L. (2013) China y el capitalismo global. Reflexiones sobre marxismo, historia y politica. Barcelona: El Viejo Topo.

Cooper R., J. (2004) The Beijing Consensus. London: The Foreign Policy Center.

Esteban, M. (2017) "La política exterior de Xi Jinping tras el $19^{\circ}$ Congreso: China quiere un papel central en la escena global". Revista ARI (Real Instituto Elcano) [En línea] [URL: $<$ http://bit.ly/2FhLd1d $>$. Consultado el 26 de febrero de 2018].

Correa López, G. \& González García, J. (2005) "La actual relación China-Estados Unidos: el vínculo económico como determinante de primera instancia”, en X. Ríos (ed.) Política

15 Ver CEPAL (2018). 
exterior de China. La diplomacia de una potencia emergente. Barcelona: Bellaterra, 107124.

FCC, Foro CELAC-China (2015) Declaración de Beijing. [URL: <http://www.chinacelacforum.org/esp/zywj_4/t1230940.htm>. Consultado el 24 de mayo de 2016].

FCC, Foro CELAC-China (2015) Plan de cooperación 2015-2019. [URL: <http://www.chinacelacforum.org/esp/zywj_4/t1230945.htm>. Consultado el 24 de mayo de 2016].

FCC, Foro CELAC-China (2018) Declaración de Santiago. [URL: < http://bit.ly/2rAmfU8>. Consultado el 23 de febrero de 2018].

Gaspar, C. (2005) "La nueva diplomacia china después del 11-S”, en X. Ríos (ed.) Política exterior de China. La diplomacia de una potencia emergente. Barcelona: Bellaterra, 4571.

Kaplan, R. (2010) “The geography of Chinese power”. Foreign Affairs, vol. 89, núm. 3, 2241.

Lee, Y. (2013) “La diplomacia pública y el «soft power» de China en América Latina”, en I. Rodríguez y Y. Shouguo (eds.) La diplomacia pública de China en América Latina. Lecciones para Chile. Santiago de Chile: RIL Editores, 71-120.

Mackinder, H. (1904) “The Geographical Pivot of History”. The Geographical Journal, vol. 23, no. 4, pp.421-437. [Trad. de Marina Díaz (2011) "El pivote geográfico de la historia". Geopolítica(s). Revista de estudios sobre espacio y poder, vol. 1, núm. 2, 301-319].

MOFA, Ministery of Foreing Affairs (2003) Posición china para la Cooperación Sur-Sur. [URL: <http://www.fmprc.gov.cn/esp/wjdt/wjzc/t25296.shtml>. Consultado el 24 de mayo de 2016].

MOFA, Ministery of Foreing Affairs (2008) Documento sobre la politica de China hacia América Latina y el Caribe. [URL: <http://bit.ly/1qWohnM>. Consultado el 24 de mayo de 2016].

MOFA, Ministery of Foreing Affairs (2011) Libro Blanco: Desarrollo Pacifico de China. [URL: <http://www.mfa.gov.cn/esp/zxxx/t862206.htm>. Consultado el 24 de mayo de 2016].

MOFA, Ministery of Foreing Affairs (2015) Discurso del Presidente Xi Jinping en la inauguración del Foro CELAC-China. [URL: $<$ http://www.fmprc.gov.cn/esp/zxxx/t1227481.shtml $>$. Consultado el 24 de mayo de 2016].

MOFA, Ministery of Foreing Affairs (2016) Documento sobre la politica de China hacia América Latina y el Caribe. [URL: <http:/www.chinacelacforum.org/esp/zywj_4/t1418613.htm>. Consultado el 24 de fe-brero de 2018].

Modelski, G. (1987) Long Cycles in World Politics. London: Macmillan.

PCCH, Partido Comunista de China (2012) Informe presentado ante el XVIII Congreso del $\mathrm{PCCH}$.

[URL: $<$ http://spanish.china.org.cn/specials/18da/201211/16/content_27137435.htm>. Consultado el 24 de mayo de 2016].

PCCH, Partido Comunista de China (2017) Informe presentado ante el XIX Congreso del $P C C H$. [URL: <http://spanish.xinhuanet.com/2017-11/03/c_136726335.htm>. Consultado el 22 de febrero de 2018].

Peng, Y. (2013) "La estrategia integral y la diplomacia pública de China en una nueva época”, en I. Rodríguez y Y. Shouguo (eds.) La diplomacia pública de China en Amé-rica Latina. Lecciones para Chile. Santiago de Chile: RIL Editores, 129-152.

Preciado, J. \& Uc, P. (2015) “América Latina frente a China y Estados Unidos: triangulación geopolítica del sistema-mundo", en A. Bialokowski, M. Cathalifaud y P. Martins 
(eds.) El pensamiento latinoamericano: diálogos en ALAS. Sociedad y Sociología. Buenos Aires: Teseo, 87-124.

Ríos, X. (ed.) (2005) Política exterior de China. La diplomacia de una potencia emergente. Barcelona: Belaterra.

Rocha Pino, M. (2006) “China en transformación: la doctrina del desarrollo pacífico”. Foro Internacional, vol. XLVI, octubre-diciembre, 693-719.

Rodríguez, I. (2013) "La diplomacia pública en las relaciones internacionales: el aporte de China”, en I. Rodríguez y Y. Shuoguo (eds.) La diplomacia pública de China en América Latina. Santiago de Chile: RIL Editores, 13-50.

Taylor, P. J. (1994) Geografía política. Economía-mundo, Estado-nación y localidad. Madrid: Trama Editorial.

Wallerstein, I. (2004) Capitalismo histórico y movimientos antisistémicos. Madrid: Akal.

Yang, E. (2005) "Mao Zedong y Deng Xiaoping: medio siglo de diplomacia china", en X. Ríos (ed.) Política exterior de China: la diplomacia de una potencia emergente. Barcelona: Bellaterra, 19-43. 